Article

\title{
Cyclodepsipeptides and Sesquiterpenes from Marine-Derived Fungus Trichothecium roseum and Their Biological Functions
}

\author{
Yuan-Ming Zhou ${ }^{1,2,+}$, Guang-Lin Ju ${ }^{1,+}$, Lin Xiao ${ }^{1}$, Xiang-Fei Zhang ${ }^{1}$ and Feng-Yu Du ${ }^{1,3, *}$ \\ 1 College of Chemistry and Pharmacy, Qingdao Agricultural University, Qingdao 266109, China; \\ zym7410@163.com (Y.-M.Z.); jgl2018666@163.com (G.-L.J.); xiaolin_qd@163.com (L.X.); \\ 88121029@163.com (X.-F.Z.) \\ 2 Analytical and Testing Center, Qingdao Agricultural University, Qingdao 266109, China \\ 3 Shandong Province Key Laboratory of Applied Mycology, Qingdao Agricultural University, Qingdao 266109, China \\ * Correspondence: fooddfy@126.com \\ + These authors contributed equally to this work.
}

Received: 24 November 2018; Accepted: 14 December 2018; Published: 19 December 2018

\begin{abstract}
On the basis of the 'one strain, many compounds' (OSMAC) strategy, chemical investigation of the marine-derived fungus Trichothecium roseum resulted in the isolation of trichomide cyclodepsipeptides (compounds 1-4) from PDB medium, and destruxin cyclodepsipeptides (compounds 5-7) and cyclonerodiol sesquiterpenes (compounds 8-10) from rice medium. The structures and absolute configurations of novel (compounds 1, 8, and 9) and known compounds were elucidated by extensive spectroscopic analyses, X-ray crystallographic analysis, and ECD calculations. All isolated compounds were evaluated for cytotoxic, nematicidal, and antifungal activities, as well as brine shrimp lethality. The novel compound 1 exhibited significant cytotoxic activities against the human cancer cell lines MCF-7, SW480, and HL-60, with IC $_{50}$ values of 0.079, 0.107 , and $0.149 \mu \mathrm{M}$, respectively. In addition, it also showed significant brine shrimp lethality, with an $\mathrm{LD}_{50}$ value of $0.48 \mu \mathrm{M}$, and moderate nematicidal activity against Heterodera avenae, with an $\mathrm{LC}_{50}$ value of $94.9 \mu \mathrm{g} / \mathrm{mL}$. This study constitutes the first report on the cytotoxic and nematicidal potential of trichomide cyclodepsipeptides.
\end{abstract}

Keywords: marine-derived fungus; cyclodepsipeptides; sesquiterpenes; cytotoxic activity; nematicidal activity

\section{Introduction}

In the search for novel bioactive metabolites from various natural resources, marine-derived fungi have gained increasing attention due to their potential capacity to produce structurally unique and biologically active metabolites [1,2]. However, metabolites isolated from marine-derived fungi generally perform far below their biosynthetic potential, indicating the existence of silent biosynthetic pathways $[3,4]$. The culture strategy of 'one strain, many compounds' (OSMAC) is able to significantly increase the chemical diversity of fungi [5-7]. One successful application was the isolation of a series of cytotoxic cytochalasins from a marine-derived fungus Spicaria elegans KLA03, via the modification of the culture media and the addition of tryptophan [8-10].

Cyclodepsipeptides of the trichomide and destruxin classes are all cyclic hexadepsipeptides containing an $\alpha$-hydroxy acid, a $\beta$-alanine, and four $\alpha$-amino acids [11-13]. The characteristic structure difference between the two classes is the replacement of the $N$-methyl-isoleucine residue in trichomides with a $N$-methyl-valine in destruxins [11,12]. In 2013, Tan and his co-workers reported the isolation of trichomides $\mathrm{A}-\mathrm{C}$ with significant immunosuppressive activities [11], 
while destruxins exhibited various biological activities, including V-ATPase inhibition [13], antiviral [14], phytotoxic [15], and insecticidal activities [16]. Cyclonerodiol sesquiterpenes, generally isolated from the genera Trichoderma and Trichothecium, have been reported to exhibit anti-inflammatory, antiallergic, and antimicrobial activities [17-19]. During the ongoing search for bioactive leading compounds [20-22], the PDB (Potato-Dextrose Broth) medium extract of a marine-derived fungus Trichothecium roseum attracted our attention because of its cytotoxic and nematicidal potential. From this extract, bioactive cyclodepsipeptides of the trichomide class (compounds 1-4) were isolated (Figure 1). Based on the 'one strain, many compounds' (OSMAC) strategy, a different rice medium extract showed a different metabolite profile and further structural types, including cyclodepsipeptides of the destruxin class (compounds 5-7) and cyclonerodiol sesquiterpenes (compounds 8-10) (Figure 1). The isolation, structural elucidation, and biological evaluation of the isolated compounds (compounds 1-10) are discussed herein.
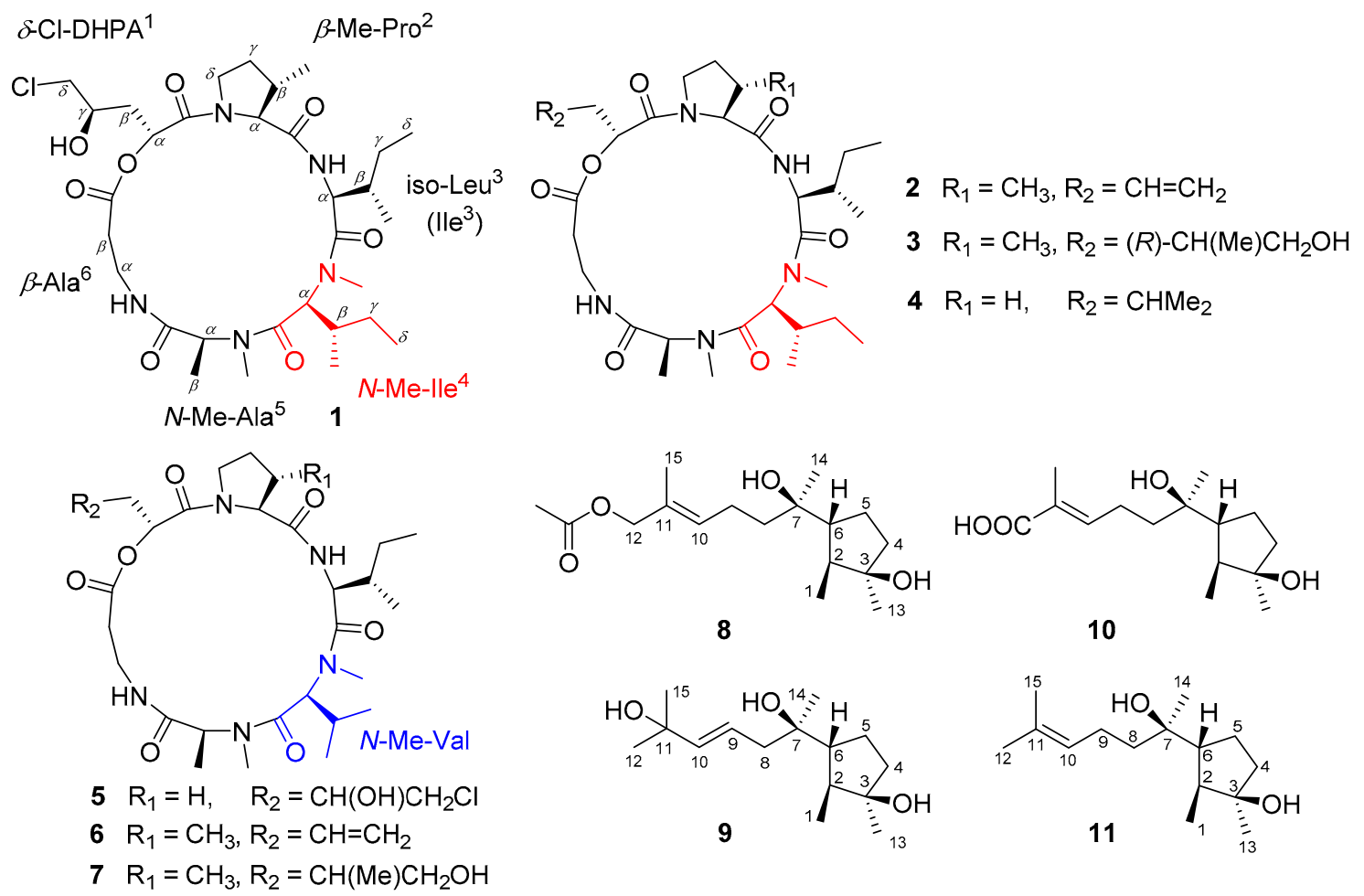

Figure 1. Compounds 1-4 from the liquid PDB medium, 5-10 from the solid rice medium, and the reference Compound 11 (cyclonerodiol).

\section{Results and Discussion}

\subsection{Structural Elucidation}

The molecular formula of trichomide D (compound 1), $\mathrm{C}_{31} \mathrm{H}_{52} \mathrm{~N}_{5} \mathrm{O}_{8} \mathrm{Cl}$, was obtained using HRESIMS (Figure S2 in the Supplementary Materials). The one-dimensional NMR data (Table 1) exhibited six carbonyl carbons $\left(\delta_{C} 173.6,173.6,172.4,172.1,170.8,170.4\right)$ and two amide $N H$ protons $\left(\delta_{\mathrm{H}} 8.56,7.03\right)$, indicating the presence of a cyclic hexadepsipeptide skeleton. 
Table 1. ${ }^{1} \mathrm{H}(500 \mathrm{MHz})$ and ${ }^{13} \mathrm{C}(125 \mathrm{MHz}) \mathrm{NMR}$ data of compound $1\left(\mathrm{CD}_{3} \mathrm{OD}, \delta\right.$ : ppm).

\begin{tabular}{|c|c|c|c|c|c|}
\hline No. & $\delta_{\mathrm{C}}$ (Type) & $\delta_{\mathrm{H}}$ (mult., $J$ in $\mathrm{Hz}$ ) & No. & $\delta_{\mathrm{C}}$ (Type) & $\delta_{\mathrm{H}}$ (mult., $J$ in $\mathrm{Hz}$ ) \\
\hline & $\delta$-Cl-DHPA ${ }^{1}$ & & & $N-\mathrm{Me}-\mathrm{Ile}^{4}$ & \\
\hline $\mathrm{CO}$ & $170.4, \mathrm{C}$ & & $\mathrm{CO}$ & $172.1, \mathrm{C}$ & \\
\hline$\alpha$ & $70.7, \mathrm{CH}$ & $5.21, \mathrm{t}(7.0)$ & $\alpha$ & $56.9, \mathrm{CH}$ & $5.09, \mathrm{~d}(11.0)$ \\
\hline$\beta$ & $34.9, \mathrm{CH}_{2}$ & $2.18, \mathrm{~m}$ & $\beta$ & $33.4, \mathrm{CH}$ & $2.06, \mathrm{~m}$ \\
\hline$\gamma$ & $67.2, \mathrm{CH}^{2}$ & $3.82, \mathrm{~m}$ & $\beta$-Me & $14.8, \mathrm{CH}_{3}$ & 0.90 , overlapped \\
\hline \multirow[t]{2}{*}{$\delta$} & $48.3, \mathrm{CH}_{2}$ & $3.61, \mathrm{~d}(5.0)$ & $\gamma$ & $25.3, \mathrm{CH}_{2}$ & $1.50, \mathrm{~m} ; 1.07, \mathrm{~m}$ \\
\hline & $\beta$-Me-Pro ${ }^{2}$ & & $\delta$ & $10.0, \mathrm{CH}_{3}$ & 0.94 , overlapped \\
\hline $\mathrm{CO}$ & $172.4, \mathrm{C}$ & & $N$-Me & $30.1, \mathrm{CH}_{3}$ & $3.21, \mathrm{~s}$ \\
\hline$\alpha$ & $67.5, \mathrm{CH}$ & $4.08, \mathrm{~m}$ & & $N-\mathrm{Me}^{-\mathrm{Ala}^{5}}$ & \\
\hline$\beta$ & $37.5, \mathrm{CH}$ & $2.55, \mathrm{~m}$ & $\mathrm{CO}$ & $170.8, \mathrm{C}$ & \\
\hline$\gamma$ & $30.6, \mathrm{CH}_{2}$ & $2.10, \mathrm{~m} ; 1.77, \mathrm{br} \mathrm{s}$ & $\alpha$ & $55.4, \mathrm{CH}$ & $5.32, q(6.5)$ \\
\hline$\delta$ & $45.4, \mathrm{CH}_{2}$ & $4.06, \mathrm{~m} ; 3.95, \mathrm{~m}$ & $\beta$ & $14.3, \mathrm{CH}_{3}$ & 1.32 , overlapped \\
\hline$\beta$-Me & $17.9, \mathrm{CH}_{3}$ & $1.16, \mathrm{~d}(6.8)$ & $\mathrm{N}-\mathrm{Me}$ & $27.5, \mathrm{CH}_{3}$ & $2.71, \mathrm{~s}$ \\
\hline $\mathrm{CO}$ & $\begin{array}{l}\mathrm{Ile}^{3} \\
\text { 173.6, C }\end{array}$ & & $\mathrm{CO}$ & $\begin{array}{l}\beta-\text { Ala }^{6} \\
173.6, \mathrm{C}\end{array}$ & \\
\hline$\alpha$ & $53.4, \mathrm{CH}$ & 4.76 , overlapped & $\alpha$ & $33.8, \mathrm{CH}_{2}$ & $2.69, \mathrm{~m} ; 2.58, \mathrm{~m}$ \\
\hline$\beta$ & $37.0, \mathrm{CH}$ & $1.94, \mathrm{~m}$ & $\beta$ & $33.4, \mathrm{CH}_{2}$ & $3.80, \mathrm{~m} ; 3.15, \mathrm{~m}$ \\
\hline$\beta$-Me & $14.3, \mathrm{CH}_{3}$ & 0.86 , overlapped & $\mathrm{NH}$ & & 8.56, br. s \\
\hline$\gamma$ & 24.6, $\mathrm{CH}_{2}$ & $\begin{array}{l}\text { 1.49, m;1.33, } \\
\text { overlapped }\end{array}$ & & & \\
\hline$\delta$ & $9.7, \mathrm{CH}_{3}$ & 0.87 , overlapped & & & \\
\hline $\mathrm{NH}$ & & $7.03, \mathrm{~d}(7.8)$ & & & \\
\hline
\end{tabular}

Further detailed analyses of one-dimensional and two-dimensional NMR data (Figures S3-S7) resulted in the identification of one $\delta$-chloro- $\alpha, \gamma$-dihydroxypentanoic acid $\left(\delta\right.$-Cl-DHPA $\left.{ }^{1}\right)$ and five amino acids, including $\beta$-Me-proline $\left(\beta\right.$-Me-Pro $\left.{ }^{2}\right)$, isoleucine $\left(\mathrm{Ile}^{3}\right), N$-Me-isoleucine $\left(N\right.$-Me-Ile $\left.{ }^{4}\right)$, $\mathrm{N}$-Me-alanine $\left(\mathrm{N}-\mathrm{Me}-\mathrm{Ala}^{5}\right)$, and $\beta$-alanine $\left(\beta-\mathrm{Ala}^{6}\right)$ residues (Figure 2). Based on the characteristic ${ }^{13} \mathrm{C}$ NMR signal of $\delta_{\mathrm{C}} 48.3$, the chlorine atom should be connected to the $\delta-\mathrm{CH}_{2}$ group in the DHPA ${ }^{1}$ residue. The above-mentioned residues were preliminarily connected by the observed HMBC cross-peaks from $\alpha-\mathrm{CH}$ or $N$-Me signals to the carbonyl carbons, indicating the presence of a cyclic hexadepsipeptide with the sequence of cyclo- $\left(\delta\right.$-Cl-DHPA $\left.{ }^{1}-\beta-\mathrm{MePro}^{2}-\mathrm{Ile}^{3}-\mathrm{NMeIle}^{4}-\mathrm{NMeAla}^{5}-\beta-\mathrm{Ala}^{6}\right)$. The structure of compound 1 was unambiguously confirmed by single-crystal X-ray diffraction using $\mathrm{Cu} \mathrm{K} \alpha$ radiation, which showed $\mathrm{R}$ configurations of both $\alpha-\mathrm{CH}$ and $\gamma-\mathrm{OH}$ in the $\delta$-Cl-DHPA ${ }^{1}$ residue (Figure 3 ). The amino acid units in compound 1 were all assigned as $L$-configured (Figure 3 ).
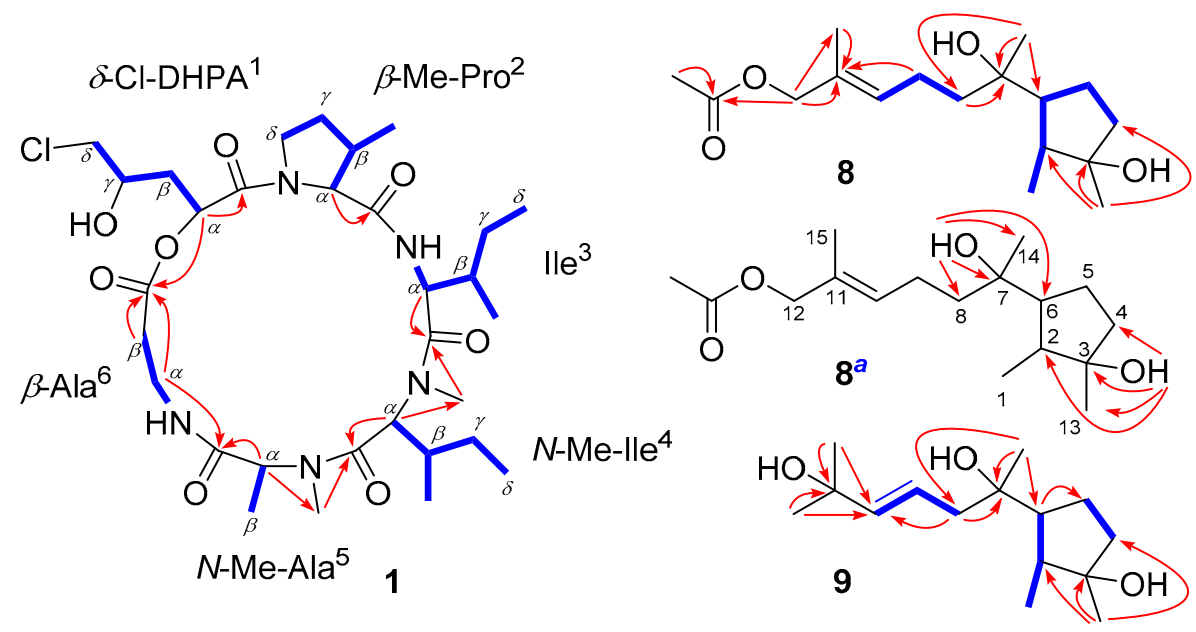

Figure 2. The key ${ }^{1} \mathrm{H}-{ }^{1} \mathrm{H}$ COSY (blue bond lines) and $\mathrm{HMBC}$ (red arrows) correlations of 1, 8, and 9. ${ }^{a}$ measured in DMSO-d6. 


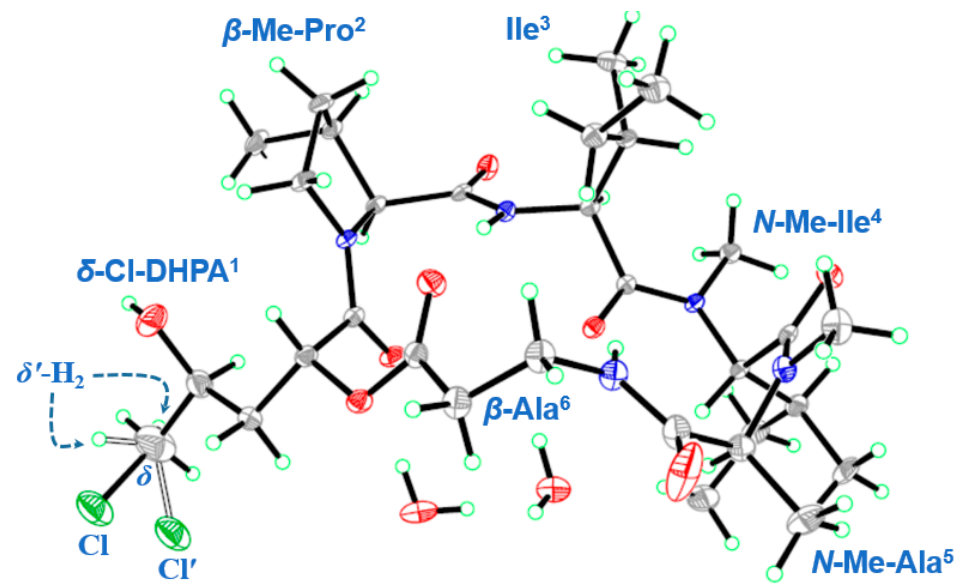

Figure 3. X-ray crystal structure of compound 1.

Cyclonerodiol C (compound 8) was confirmed to have the molecular formula $\mathrm{C}_{17} \mathrm{H}_{30} \mathrm{O}_{4}$ by its HRESIMS data (Figure S8), implying three degrees of unsaturation. The one-dimensional NMR (Figures S9 and S10) and HSQC spectra (Figure S12) showed the characteristic signals of one carbonyl $\left(\mathrm{CO}, \delta_{\mathrm{C}} 171.5\right)$ and two olefinic carbons $\left(\mathrm{CH}, \delta_{\mathrm{C}} 129.6 / \delta_{\mathrm{H}} 5.47\right.$ and $\left.\mathrm{C}, \delta_{\mathrm{C}} 129.9\right)$ (Table 2$)$, which were responsible for two degrees of unsaturation. Therefore, a remaining degree of unsaturation due to one carbon ring can be deduced. The consecutive COSY cross-peaks (Figure S11) from H-1 to H-2, 6, 5, and 4, as well as the HMBC peaks (Figure S13) from H-13 to C-2, 3, and 4, could be identified as one cyclopentane residue (Figure 2). Detailed analyses of the one- and two-dimensional NMR data (Figures S9-S13) suggested that the structure of compound 8 was similar to that of cyclonerodiol (compound 11), except that the signals of the methyl group $\left(\delta_{\mathrm{C}} 26.1 / \delta_{\mathrm{H}} 1.67\right)$ in cyclonerodiol (compound 11) were absent from the ${ }^{1} \mathrm{H}$ and ${ }^{13} \mathrm{C}$ NMR spectra of compound 8 [23]. Instead, additional oxymethylene $\left(\mathrm{CH}_{2}, \delta_{\mathrm{C}} 69.9 / \delta_{\mathrm{H}} 4.45\right)$ and acetoxyl groups $\left(\mathrm{CH}_{3}, \delta_{\mathrm{C}} 19.4 / \delta_{\mathrm{H}} 2.08\right.$ and $\left.\mathrm{CO}, \delta_{\mathrm{C}} 171.5\right)$ were observed in the spectrum of compound 8 (Table 2). The key HMBC correlation between H-12 and the carbonyl carbon further confirmed the linkage between C-12 and the acetoxyl group (Figure 2). The NMR data of compound 8 (Figures S14-S17) were also measured in DMSO-d6, showing two $\mathrm{OH}$ signals of $\delta_{\mathrm{H}} 3.81$ and 3.89 (Table S1). The connections between $3-\mathrm{OH}\left(\delta_{\mathrm{H}} 3.81\right)$ and $\mathrm{C}-3$, as well as between $7-\mathrm{OH}\left(\delta_{\mathrm{H}} 3.89\right)$ and $\mathrm{C}-7$, were confirmed by the HMBC cross-peaks from 3-OH to C-3, 4, and 13 , as well as from $7-\mathrm{OH}$ to $\mathrm{C}-7,8$, and 14 , respectively (Figure 2).

Table 2. ${ }^{1} \mathrm{H}(500 \mathrm{MHz})$ and ${ }^{13} \mathrm{C}(125 \mathrm{MHz})$ NMR data of compounds 8 and $9(\delta: \mathrm{ppm}){ }^{\text {a }}$.

\begin{tabular}{|c|c|c|c|c|c|}
\hline \multicolumn{3}{|c|}{ Compound 8} & \multicolumn{3}{|c|}{ Compound 9} \\
\hline No. & $\delta_{\mathrm{C}}$ (Type) & $\delta_{\mathrm{H}}$ (mult., $J$ in $\mathrm{Hz}$ ) & No. & $\delta_{\mathrm{C}}$ (Type) & $\delta_{\mathrm{H}}$ (mult., $J$ in $\mathrm{Hz}$ ) \\
\hline 1 & $14.0, \mathrm{CH}_{3}$ & $1.05(6.6)$ & 1 & $14.5, \mathrm{CH}_{3}$ & $1.05(6.8)$ \\
\hline 2 & $44.1, \mathrm{CH}$ & $1.57, \mathrm{~m}$ & 2 & $44.3, \mathrm{CH}$ & $1.61, \mathrm{~m}$ \\
\hline 3 & $80.7, \mathrm{C}$ & & 3 & $81.4, \mathrm{C}$ & \\
\hline 4 & $40.0, \mathrm{CH}_{2}$ & $1.63, \mathrm{~m} ; 1.55, \mathrm{~m}$ & 4 & $40.4, \mathrm{CH}_{2}$ & $1.68, \mathrm{~m} ; 1.53, \mathrm{~m}$ \\
\hline 5 & $23.8, \mathrm{CH}_{2}$ & $1.85, \mathrm{~m} ; 1.60, \mathrm{~m}$ & 5 & $24.4, \mathrm{CH}_{2}$ & $1.86, \mathrm{~m} ; 1.61, \mathrm{~m}$ \\
\hline 6 & $54.1, \mathrm{CH}$ & $1.87, \mathrm{~m}$ & 6 & $54.2, \mathrm{CH}$ & $1.86, \mathrm{~m}$ \\
\hline 7 & $74.1, \mathrm{C}$ & & 7 & $74.5, \mathrm{C}$ & \\
\hline 8 & $40.0, \mathrm{CH}_{2}$ & $1.52, \mathrm{t}(8.4)$ & 8 & $43.4, \mathrm{CH}_{2}$ & $2.20, \mathrm{~m}$ \\
\hline 9 & $22.0, \mathrm{CH}_{2}$ & $2.13, \mathrm{~m}$ & 9 & $122.1, \mathrm{CH}$ & 5.70, overlapped \\
\hline 10 & $129.6, \mathrm{CH}$ & $5.47, \mathrm{t}(7.0)$ & 10 & $142.3, \mathrm{CH}$ & 5.70, overlapped \\
\hline 11 & $129.9, \mathrm{C}$ & & 11 & $70.8, \mathrm{C}$ & \\
\hline 12 & $69.9, \mathrm{CH}_{2}$ & $4.45, \mathrm{~s}$ & 12 & $29.9, \mathrm{CH}_{3}$ & $1.33, \mathrm{~s}$ \\
\hline 13 & $24.7, \mathrm{CH}_{3}$ & $1.26, \mathrm{~s}$ & 13 & $26.1, \mathrm{CH}_{3}$ & $1.25, \mathrm{~s}$ \\
\hline 14 & $23.2, \mathrm{CH}_{3}$ & $1.17, \mathrm{~s}$ & 14 & $25.2, \mathrm{CH}_{3}$ & $1.13, \mathrm{~s}$ \\
\hline 15 & $12.5, \mathrm{CH}_{3}$ & $1.67, \mathrm{~s}$ & 15 & $29.9, \mathrm{CH}_{3}$ & $1.33, \mathrm{~s}$ \\
\hline $\mathrm{COCH}_{3}$ & $19.4, \mathrm{CH}_{3}$ & $2.08, \mathrm{~s}$ & & & \\
\hline $\mathrm{C}=\mathrm{O}$ & $171.5, \mathrm{C}$ & & & & \\
\hline
\end{tabular}


The molecular formula of compound 9, $\mathrm{C}_{15} \mathrm{H}_{28} \mathrm{O}_{3}$, was determined via HRESIMS (Figure S19). The one-dimensional NMR (Figures S20 and S21) and HSQC (Figure S23) data exhibited marked similarities to those of cyclonerodiol (compound 11) [23], except for the chemical shifts of the two olefinic carbons $\left(\mathrm{CH}-9, \delta_{\mathrm{C}} 122.1 / \delta_{\mathrm{H}} 5.70\right.$ and $\left.\mathrm{CH}-10, \delta_{\mathrm{C}} 142.3 / \delta_{\mathrm{H}} 5.70\right)$, and the presence of another oxygenated quaternary carbon $\left(\mathrm{C}-11, \delta_{\mathrm{C}} 70.8\right)$ in compound 9 (Table 2). $\mathrm{CH}-9$ in the double bond was connected to $\mathrm{CH}_{2}-8$, based on the COSY correlation (Figure S22) between $\mathrm{H}-8$ and H-9, while $\mathrm{CH}-10$ was linked to the quaternary C-11 by the key HMBC cross-peaks (Figure S24) from H-12 and 15 to C-10 and C-11. Thus, the planar structure of compound 9 was confirmed, and it was named cyclonerodiol D.

The relative configuration of the cyclopentane residue in compound 8 was deduced by the NOESY experiment (Figure 4 and Figure S18). The key NOE correlation between $\mathrm{H}_{3}-13$ and $\mathrm{H}-2$ suggested an $\alpha$ orientation of these protons, while the cross-peaks from $\mathrm{H}_{3}-1$ to $\mathrm{H}-6$ and 3-OH indicated a $\beta$ orientation. The E-geometry for the double bond in compound 8 was also confirmed by the NOE correlation between $\mathrm{H}-10$ and $\mathrm{H}_{2}-12$. The relative configuration of C-7 in compound 8 was initially assigned via the NOE cross-peaks from $\mathrm{H}_{3}-14$ to $\mathrm{H}-2$, from $7-\mathrm{OH}$ to $\mathrm{H}_{3}-1$, and from $\mathrm{H}_{2}-8$ to $\mathrm{H}_{2}-5$ (Figure 4, Figure S18), which suggested that the rotation of the single bond C6-C7 was restricted by the surrounding groups [24]. Although the specific rotation of compound 8 was similar to that of cyclonerodiol (compound 11) $\left([\alpha]_{\mathrm{D}}^{24}=-28.3, \mathrm{c} 0.86\right.$ for 8 versus $\left[[\alpha]_{\mathrm{D}}^{24}=-21.0, c 1.04\right.$ for cyclonerodiol, both determined in $\mathrm{CHCl}_{3}$ ) [23], evidence for the absolute configuration of compound 8 was still weak. However, the biosynthetic pathway of cyclonerodiol (compound 11) in T. roseum had been already confirmed [25-27], suggesting that the cyclonerodiol sesquiterpene compound 8 could also been biosynthesized via the same pathway in T. roseum. Therefore, the plausible biosynthetic pathway of compound 8 was deduced from cyclonerodiol (compound 11), further indicating the same absolute configurations between compounds 8 and 11 (Figure 5). In addition, comparison of the NMR data between compound 8 and cyclonerodiol (compound 11) showed marked similarities. Based on the above-mentioned analyses, the absolute configuration of compound 8 is likely the same as cyclonerodiol (compound 11). On the basis of the same analyses of NOE correlations and the plausible biosynthetic pathway of compound 9 (Figure 5), its absolute configuration is likely also the same as that of compound 8 and cyclonerodiol (compound 11). Although the cotton effects (CEs) from $200 \mathrm{~nm}$ to $240 \mathrm{~nm}$ in the measured CD spectrum of compound 9 were relatively low, its CEs (negative CE near $210 \mathrm{~nm}$, and positive CE near $230 \mathrm{~nm}$ ) were very similar to those of the calculated CD spectrum. The result of this ECD (Electronic Circular Dichroism) calculation, more or less confirms the absolute configuration of compound 9 as $2 S, 3 R, 6 R, 7 R$, and $9 E$ (Figure S25). Detailed methods of the ECD calculation are also described in the Supplementary Materials.

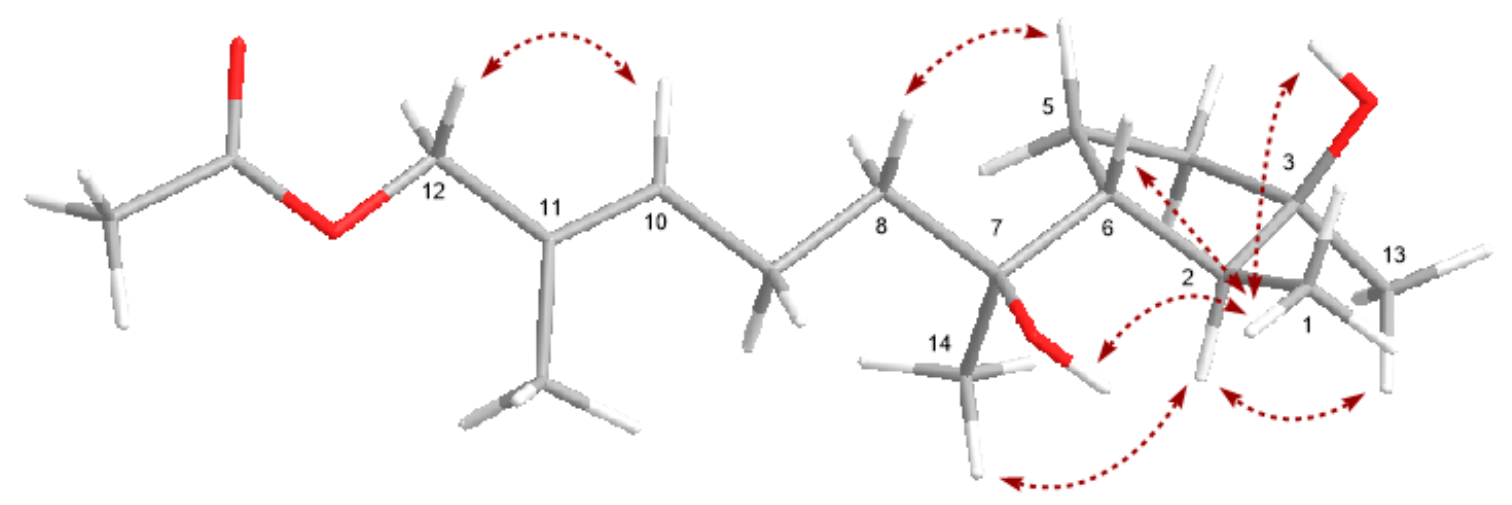

Figure 4. Key NOE correlations of compound 8. 


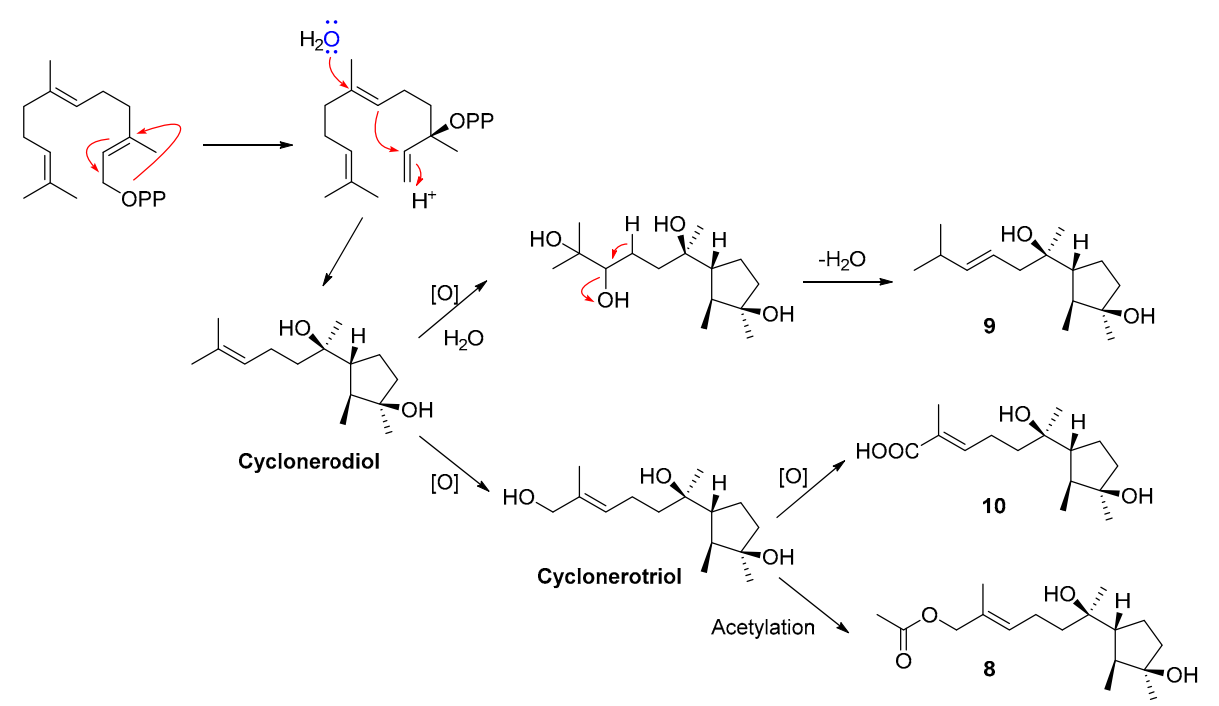

Figure 5. Plausible biosynthetic pathways of cyclonerodiol sesquiterpenes, compounds 8-10.

Besides the above-mentioned three novel compounds (compounds 1, 8, and 9), three known trichomide cyclodepsipeptides were isolated from the PDB medium: destruxin A5 (compound 2) [11], trichomide A (compound 3) [11], and homodestruxin B (compound 4) [11]. Three typical destruxin cyclodepsipeptides, destruxin chlorohydrin (compound 5) [28], roseotoxin B (compound 6) [29], and C (compound 7) [30], and one cyclonerodiol sesquiterpene, ascotrichic acid (compound 10) [31] were isolated from the rice medium. The structures of these compounds were determined by detailed analyses of their spectroscopic data and comparisons with previously published reports.

\subsection{Biological Evaluation}

The novel compounds (compounds 1, 8, and 9) were evaluated for their cytotoxic activities against five human cancer cell lines (MCF-7, SW480, HL-60, A-549, and SMMC-7721) [32-34]. Compound 1 showed significant cytotoxicity against MCF-7, SW480, and HL-60, with $\mathrm{IC}_{50}$ values of $0.079,0.107$, and $0.149 \mu \mathrm{M}$, respectively_-better than the positive control of cisplatin (Table 3). However, compounds 8 and 9 were inactive in the cytotoxic assay $\left(\mathrm{IC}_{50}>40 \mu \mathrm{M}\right)$. This is the first report on the cytotoxic activity of trichomide cyclodepsipeptides. Although the cytotoxic mechanisms of trichomides have not yet been revealed, the cytotoxic mechanisms of the structurally similar destruxins have been reported to be associated with the inhibition of the phosphoinositide-3-kinase (PI3K)/Akt pathway, and the disturbance of the intracellular redox balance. Therefore, trichomide cyclodepsipeptides might show the similar cytotoxic mechanisms to destruxins $[13,35]$.

Table 3. Cytotoxicity of the new compound 1 against five human cancer cell lines $\left(\mathrm{IC}_{50}: \mu \mathrm{M}\right)$.

\begin{tabular}{cccccc}
\hline Compound & MCF-7 & SW480 & HL-60 & A-549 & SMMC-7721 \\
\hline 1 & $0.079 \pm 0.004$ & $0.107 \pm 0.015$ & $0.149 \pm 0.007$ & $>40$ & $>40$ \\
Cisplatin & $19.44 \pm 1.57$ & $20.80 \pm 1.04$ & $3.72 \pm 0.09$ & $16.97 \pm 0.69$ & $12.35 \pm 0.52$ \\
\hline
\end{tabular}

Brine shrimp (Artemia salina), an aquatic species characterized by high sensibility to toxins, can be used as a model organism for quick preliminary insecticidal screening [36,37]. Therefore, in order to identify the leading insecticidal compounds, all of the isolated compounds (compounds 1-10) were evaluated for lethal activity against brine shrimp, and furthermore, for nematicidal activity against Heterodera avenae [38] (Table 4). In the brine shrimp assay, the cyclodepsipeptide compounds 1, 2, and 4-6 exhibited significant lethal activity, with $\mathrm{LD}_{50}$ values of $0.48,0.74,3.22,2.47$, and 2.81 $\mu \mathrm{M}$, respectively. The nematicidal assay showed that compounds 1 and 2 exhibited moderate activity, with $\mathrm{LC}_{50}$ values of 94.9 and $143.6 \mu \mathrm{g} / \mathrm{mL}$, respectively. Compounds 1 and 2 exhibited 
obviously better insecticidal and nematicidal activity against brine shrimp and H. avenae than the other cyclodepsipeptides, which was probably due to the structural diversity of the DHPA ${ }^{1}$ residues and the presence of $\mathrm{N}-\mathrm{Me}-\mathrm{Ile}{ }^{4}$ residue in the trichomide cyclodepsipeptides.

Table 4. Brine shrimp lethality $\left(\mathrm{LD}_{50}, \mu \mathrm{M}\right)$ and nematicidal activity $\left(\mathrm{LC}_{50}, \mu \mathrm{g} / \mathrm{mL}\right)$ of compounds $1-10$.

\begin{tabular}{|c|c|c|c|c|c|c|c|c|c|c|c|}
\hline & 1 & 2 & 3 & 4 & 5 & 6 & 7 & 8 & 9 & 10 & Positive Control \\
\hline brine shrimp lethality & 0.48 & 0.74 & $>50$ & 3.22 & 2.47 & 2.81 & $>50$ & n.a. & n.a. & n.a. & $8.4^{\mathrm{a}}$ \\
\hline nematicidal activity & 94.9 & 143.6 & $>500$ & 221.8 & 207.7 & 293.4 & $>500$ & n.a. & n.a. & n.a. & $23.1^{b}$ \\
\hline
\end{tabular}

n.a.: no activity. ${ }^{\mathrm{a}, \mathrm{b}}$ colchicine for brine shrimp lethality and abamectin for the nematicidal bioassay.

However, only compound 9 showed moderate antifungal activity against Valsa mali, with an MIC value of $64 \mu \mathrm{g} / \mathrm{mL}$. The trichomides (compounds 1 and 4 ) and sesquiterpene (compound 8) exhibited weak bioactivities against $V$. mali and Rhizoctonia cerealis, with MIC values from 128 to $256 \mu \mathrm{g} / \mathrm{mL}$ (Table S2). None of the isolated compounds exhibited activity against Fusarium. oxysporum f. sp. vasinfectum.

\section{Experimental Section}

\subsection{General Procedures}

One- and two-dimensional NMR spectra were recorded at $500 \mathrm{MHz}$ and $125 \mathrm{MHz}$ for ${ }^{1} \mathrm{H}$ and ${ }^{13} \mathrm{C}$ respectively, using a Bruker Avance III spectrometer (Bruker Biospin Group, Karlsruhe, Germany) with TMS as internal standard. HRESIMS were determined using a Bruker impact II ESI-QTOF mass spectrometer (Bruker Daltonik, Bremen, Germany). Optical rotations were obtained using a Jasco P-1020 digital polarimeter (Jasco Corporation, hachioji-shi, Tokyo, Japan). ECD spectra were acquired using a Chirascan spectropolarimeter (Applied Photophysics Ltd., Surrey, UK). Column chromatography (CC) was performed with Si gel (200-300 mesh; Qingdao Haiyang Chemical Co., Qingdao, Shandong, China), Lobar LiChroprep RP-18 (40-63 $\mu \mathrm{m}$; Merck, Kenilworth, NJ, USA), and Sephadex LH-20 (18-110 $\mu \mathrm{m}$; Merck, Kenilworth, NJ, USA). Semi-preparative HPLC was performed using a Dionex HPLC system equipped with a P680 pump, an ASI-100 automated sample injector, and a UVD340U multiple wavelength detector controlled using Chromeleon software, version 6.80 (Dionex Corporation, Sunnyvale, CA, USA).

\subsection{Fungal Material}

The fungal strain T. roseum was isolated from marine driftwood collected from the intertidal zone of Lingshan Island, Qingdao, China in November 2013. The fungus was identified on the basis of morphological characteristics and molecular analyses of ITS [20]. The strain was preserved in the Natural Products Laboratory, College of Chemistry and Pharmacy, Qingdao Agricultural University.

\subsection{Fermentation and HPLC Analyses}

Fresh mycelia of the fungus were statically fermented at $28^{\circ} \mathrm{C}$ for 30 days on the liquid PDB and solid rice media. The liquid culture was conducted in $40 \times 1 \mathrm{~L}$ conical flasks containing $300 \mathrm{~mL}$ of PDB medium (1000 $\mathrm{mL}$ natural seawater, 20 g glucose, and $200 \mathrm{~mL}$ potato juice, $\mathrm{pH} 6.5-7.0)$, while the solid one was kept in $40 \times 1 \mathrm{~L}$ flasks containing rice ( $100 \mathrm{~g} /$ flask $)$, peptone $(0.6 \mathrm{~g} / \mathrm{flask})$, and natural seawater $(100 \mathrm{~mL} /$ flask).

Ethyl acetate (EtOAc) extracts of the two fermentations were analyzed using HPLC with a MeOH-H $\mathrm{H}_{2} \mathrm{O}$ eluting gradient and a detection wavelength of $225 \mathrm{~nm}$ (Figure S1). Details are described in the Supplementary Materials.

\subsection{Extraction and Isolation}

The PDB culture was exhaustively extracted using EtOAc to obtain a crude extract, which was fractionated via silica gel vacuum liquid chromatography (VLC) with a chloroform/MeOH gradient 
(100:1, 50:1, 20:1, and 10:1) to yield four fractions (Frs. 1-4). Fr. 3 was purified via CC over RP-C18, eluting with a $\mathrm{MeOH}-\mathrm{H}_{2} \mathrm{O}$ gradient (from 2:8 to 1:0) to obtain three subfractions (Fr. 3-1 to 3-3). Fr. 3-2

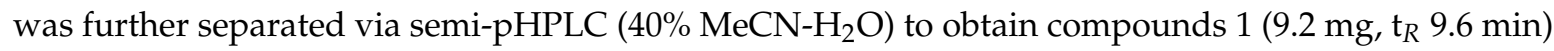
and $3\left(11.9 \mathrm{mg}, \mathrm{t}_{R} 13.1 \mathrm{~min}\right)$. Fr. $3-3$ was also purified, using semi-pHPLC (65\% MeOH- $\left.\mathrm{H}_{2} \mathrm{O}\right)$, to yield compounds $2\left(10.6 \mathrm{mg}, \mathrm{t}_{R} 15.4 \mathrm{~min}\right)$ and $4\left(18.1 \mathrm{mg}, \mathrm{t}_{R} 11.5 \mathrm{~min}\right)$.

The EtOAc extract of the rice fermentation was fractionated via using the same above-mentioned method to obtain four fractions (Frs. 1-4). Fr. 3 was purified via CC over RP-C18, eluting with a MeOH- $\mathrm{H}_{2} \mathrm{O}$ gradient (from 2:8 to 1:0) to obtain four subfractions (Fr. 3-1 to 3-4). Fr. 3-2 was further separated via CC over silica gel, eluting with a petroleum ether-acetone gradient (10:1, 5:1, 2:1, and 1:1) to yield compounds $8(4.3 \mathrm{mg}), 9(2.1 \mathrm{mg})$, and $10(3.4 \mathrm{mg})$. Compound $5(14.3 \mathrm{mg})$ was prepared from Fr. 3-3 using semi-pHPLC (45\% $\left.\mathrm{MeOH}-\mathrm{H}_{2} \mathrm{O}\right)$, while compounds $6(7.7 \mathrm{mg})$ and $7(6.2 \mathrm{mg})$ were purified from Fr. 3-4 using Sephadex LH-20 (Acetone) and semi-pHPLC (55\% MeOH- $\mathrm{H}_{2} \mathrm{O}$ ).

Trichomide $D$ (compound 1): Colorless crystal. Melting point $221-222{ }^{\circ} \mathrm{C} ;\left[[\alpha]_{\mathrm{D}}^{24}=-78.2\right.$, c $0.35, \mathrm{MeOH} ;{ }^{1} \mathrm{H}$ and ${ }^{13} \mathrm{C}$ NMR data, see Table 1; HRESIMS $m / z 680.3399[\mathrm{M}+\mathrm{Na}]^{+}$(calcd for $\left.\mathrm{NaC}_{31} \mathrm{H}_{52} \mathrm{~N}_{5} \mathrm{O}_{8} \mathrm{Cl}, 680.3397\right)$.

Cyclonerodiol C (compound 8): White powder. $[\alpha]_{\mathrm{D}}^{24}=-28.3, c 0.86, \mathrm{CHCl}_{3} ;{ }^{1} \mathrm{H}$ and ${ }^{13} \mathrm{C}$ NMR data, see Table 2 and Table S1; HRESIMS $m / z$ 321.2042 [M + Na] $]^{+}$(calcd for $\mathrm{NaC}_{17} \mathrm{H}_{30} \mathrm{O}_{4}, 321.2036$ ).

Cyclonerodiol D (compound 9): White powder. $\left[[\alpha]_{\mathrm{D}}^{24}=-32.6, c 1.03, \mathrm{CHCl}_{3} ;{ }^{1} \mathrm{H}\right.$ and ${ }^{13} \mathrm{C} \mathrm{NMR}$ data, see Table 2; HRESIMS $m / z 279.1930[\mathrm{M}+\mathrm{Na}]^{+}$(calcd for $\mathrm{NaC}_{15} \mathrm{H}_{28} \mathrm{O}_{3}, 279.1931$ ).

\subsection{Crystal Structure Determination}

A colorless single crystal of compound 1 was obtained by the slow evaporation of a methanol solution (containing trace water), thus, its crystal structure contained two molecules of $\mathrm{H}_{2} \mathrm{O}$. $\mathrm{H}_{2} \mathrm{O}$ molecules can form intermolecular hydrogen bonds with the cyclodepsipeptide compound 1 , which was helpful to the crystallization of the compound. All crystallographic data were collected at $150.01 \mathrm{~K}$ on a Bruker Smart-1000 CCD diffractometer (Bruker-AXS, Saarbrucken, Germany) equipped with graphite-monochromatic $\mathrm{Cu}-\mathrm{K} \alpha$ radiation $(\lambda=1.54178 \AA$ ). The adsorption data were obtained using the program SADABS [39]. The structures were elucidated by direct methods, using the SHELXTL software package [40]. All non-hydrogen atoms were refined with anisotropic displacement parameters. The hydrogen atoms were located via geometrical calculations, and their positions and thermal parameters were fixed during structure refinement. The structures were refined using full-matrix least-squares techniques [41]. Crystallographic data of compound 1 was deposited in the Cambridge Crystallographic Data Centre as CCDC 1858313.

Crystal data for compound 1: $\mathrm{C}_{31} \mathrm{H}_{52} \mathrm{~N}_{5} \mathrm{O}_{8} \mathrm{Cl} \cdot 2 \mathrm{H}_{2} \mathrm{O}, \mathrm{FW}=694.25$, Monoclinic, space group P 1211 , unit cell dimensions $a=10.1814(3) \AA, b=11.3775(4) \AA, c=15.5997(5) \AA, \alpha=\beta=\gamma=90^{\circ}, \mathrm{V}=1806.82(10)$ $\AA^{3}, Z=2, d_{\text {calcd }}=1.276 \mathrm{mg} / \mathrm{m}^{3}$, crystal dimensions $0.32 \times 0.25 \times 0.14 \mathrm{~mm}, \mu=1.436 \mathrm{~mm}^{-1}, F(000)=748$. The 26927 measurements yielded 6124 independent reflections after equivalent data were averaged, and Lorentz and polarization corrections were applied. The final refinement yielded $R_{1}=0.0489$ and $w R_{2}=0.1237[I>2 \sigma(I)]$. The Flack parameter was $0.024(13)$ in the final refinement for all 6124 reflections with 443 Friedel pairs. There were also crystallographic disorders of $\delta-\mathrm{CH}_{2}-\mathrm{Cl} / \delta^{\prime}-\mathrm{CH}_{2}-\mathrm{Cl}$ in the residue of $\delta$-Cl-DHPA ${ }^{1}$, probably due to the flexibility of the $\delta$-Cl-DHPA ${ }^{1}$ residue.

\subsection{Cytotoxicity against Human Cancer Cell Lines}

The in vitro cytotoxic effects of the novel compounds 1,8 , and 9 were evaluated on five human cancer cell lines using the MTT (3-(4,5-dimethylthiazol-2-yl)-2,5-diphenyltetrazolium bromide) method [32-34]. The human cancer cell lines were as follows: HL-60, human myeloid leukemia; A-549, lung cancer; MCF-7, breast cancer; SW-480, human colon cancer; and SMMC-7721, liver cancer. All cells were cultured in RPMI-1640 medium containing 10\% fetal bovine serum (FBS), and kept in a humidified atmosphere containing $5 \% \mathrm{CO}_{2}$ ayt $37^{\circ} \mathrm{C}$. The novel compounds and the cisplatin positive control were dissolved and diluted in DMSO to obtain sample solvents with a series of 
different concentrations. In brief, the cell suspensions $\left(200 \mu \mathrm{L}, 5 \times 10^{4}\right.$ cells $\left./ \mathrm{mL}\right)$ were seeded into 96-well culture plates and kept at $37^{\circ} \mathrm{C}$ for $12 \mathrm{~h}$, then the sample solvents $(20 \mu \mathrm{L})$ were added into each well and further cultured at $37^{\circ} \mathrm{C}$ for $24 \mathrm{~h}$. Subsequently, MTT $(100 \mu \mathrm{g})$ was added into each well and incubated at $37^{\circ} \mathrm{C}$ for $4 \mathrm{~h}$. After removal of the $100 \mu \mathrm{L}$ culture medium, the cells were lysed with $20 \%$ SDS-50\% DMF $(100 \mu \mathrm{L})$. The remaining lysates were subjected to measurements of the optical density at $595 \mathrm{~nm}$ with a 96-well microtiter plate reader. Reed and Muench's method was used to calculate $\mathrm{IC}_{50}$ values [32].

\subsection{Brine Shrimp Lethality and Nematicidal Activity}

Brine shrimp (Artemia salina) toxicity was evaluated as previously reported [36,37]. The plant-parasitic nematode $H$. avenae was selected for nematicidal bioassay using 24-well plates. Second stage juveniles (J2s) of H. avenae were collected to prepare the nematode suspension based on the protocol reported previously [34]. The isolated compounds (1-10) and abamectin positive control were dissolved and diluted in DMSO to obtain sample solvents with a series of different concentrations. The sample solvents $(5 \mu \mathrm{L})$ were added to separate wells with the nematode suspension (495 $\mu \mathrm{L})$, containing about $100 \mathrm{~J} 2 \mathrm{~s}$, while the same amount of DMSO $(5 \mu \mathrm{L})$ was added for the negative control. The plates were maintained at $25^{\circ} \mathrm{C}$ for $48 \mathrm{~h}$, and then observed using a stereomicroscope to evaluate the nematode mortalities. Nematodes were defined to be dead if their bodies became straight and did not react to mechanical touches [38]. The experiment was repeated three times under the same conditions.

\subsection{Antifungal Activity}

The isolated compounds (1-10) were also evaluated for antifungal activity against three plant pathogenic fungi, R. cerealis, V. mali, and F. oxysporum f. sp. vasinfectum, using the broth microdilution method $[34,42]$.

\section{Conclusions}

The chemical investigation of marine-derived fungus T. roseum resulted in isolation of trichomide cyclodepsipeptides (compounds 1-4) from the liquid PDB medium, and, based on the OSMAC culture strategy, isolation of destruxin cyclodepsipeptides (compounds 5-7) and cyclonerodiol sesquiterpenes (compounds 8-10) from solid rice medium. The absolute configuration of novel compound 1 was determined by single crystal X-ray diffraction analysis, while the configurations of compounds 8 and 9 were determined by NOESY experiments, comparisons of specific rotations, ECD calculation, and plausible biosynthetic pathways. The novel compound 1 exhibited significant cytotoxic activities against human cancer cell lines MCF-7, SW480, and HL-60, with IC 50 values of $0.079,0.107$, and $0.149 \mu \mathrm{M}$, respectively. In addition, it also showed significant brine shrimp lethality with an $\mathrm{LD}_{50}$ value of $0.48 \mu \mathrm{M}$, and moderate nematicidal activity against $H$. avenae with an $\mathrm{LC}_{50}$ value of $94.9 \mu \mathrm{g} / \mathrm{mL}$. Its cytotoxic, brine shrimp lethality and nematicidal activities suggest potential applications in the areas of medicine and agriculture. This is also the first time the cytotoxic and nematicidal potential of trichomide cyclodepsipeptides has been reported.

Supplementary Materials: The following are available online at http:/ /www.mdpi.com/1660-3397/16/12/519/ s1, Table S1: ${ }^{1} \mathrm{H}(500 \mathrm{MHz})$ and ${ }^{13} \mathrm{C}(125 \mathrm{MHz}) \mathrm{NMR}$ data of compound 8 (DMSO-d6); Table S2: Antifungal activities of compounds 1-10 (MIC, $\mu \mathrm{g} / \mathrm{mL}$ ); Figure S1: HPLC analyses of crude extracts of the liquid PDB and solid rice media; Figures S2, S8, and S19: HRESIMS spectrum of compound 1, 8, and 9, respectively; Figures S3-S7, S9-S18, and S20-S24: annotated 1D NMR and selected 2D NMR spectra of 1, 8, and 9; Figure S25: Comparison of ECD spectrum for $(2 S, 3 R, 6 R, 7 R$, and $9 E)-9$ with the experimental one of 9 in $\mathrm{MeOH}$.

Author Contributions: Y.-M.Z. determined the structures of the isolated compounds and prepared the manuscript; G.-L.J. performed the experiments for the isolation and bioactivity evaluation of compounds 1-10; L.X. contributed to the cytotoxic evaluation; X.-F.Z. performed the HPLC analyses of the crude extracts; F.-Y.D. supervised the research and revised the manuscript. 
Funding: This research was funded by the Natural Science Foundation of China (No. 31401795), Shandong Province Key Research and Development Project (No. 2016GSF121007 and 2018GSF121036), Qingdao Applied Fundamental Research Project (No. 15-9-1-29-jch), and High-level Talents Foundation of Qingdao Agricultural University (No. 631419 and No. 631431).

Conflicts of Interest: The authors declare no conflict of interest.

\section{References}

1. Cantrell, C.L.; Dayan, F.E.; Duke, S.O. Natural products as sources for new pesticides. J. Nat. Prod. 2012, 75, 1231-1242. [CrossRef] [PubMed]

2. Rateb, M.E.; Ebel, R. Secondary metabolites of fungi from marine habitats. Nat. Prod. Rep. 2011, 28, $290-344$. [CrossRef] [PubMed]

3. Rutledge, P.J.; Challis, G.L. Discovery of microbial natural products by activation of silent biosynthetic gene clusters. Nat. Rev. Microbiol. 2015, 13, 509-523. [CrossRef] [PubMed]

4. Takahashi, J.A.; Teles, A.P.C.; Bracarense, A.A.P.; Gomes, D.C. Classical and epigenetic approaches to metabolite diversification in filamentous fungi. Phytochem. Rev. 2013, 12, 773-789. [CrossRef]

5. Bode, H.B.; Bethe, B.; Höfs, R.; Zeeck, A. Big effects from small changes: Possible ways to explore nature's chemical diversity. Chembiochem 2002, 3, 619-627. [CrossRef]

6. Zhang, Q.; Wang, S.Q.; Tang, H.Y.; Li, X.J.; Zhang, L.; Xiao, J.; Gao, Y.Q.; Zhang, A.L.; Gao, J.M. Potential allelopathic indole diketopiperazines produced by the plant endophytic Aspergillus fumigatus using the one strain-many compounds method. J. Agric. Food Chem. 2013, 61, 11447-11452. [CrossRef] [PubMed]

7. Wang, W.X.; Kusari, S.; Laatsch, H.; Golz, C.; Kusari, P.; Strohmann, C.; Kayser, O.; Spiteller, M. Antibacterial azaphilones from an endophytic fungus, Colletotrichum sp. BS4. J. Nat. Prod. 2016, 79, 704-710. [CrossRef]

8. Liu, R.; Lin, Z.J.; Zhu, T.J.; Fang, Y.C.; Gu, Q.Q.; Zhu, W.M. Novel open-chain cytochalsins from the marine-derived fungus Spicaria elegans. J. Nat. Prod. 2008, 71, 1127-1132. [CrossRef]

9. Lin, Z.J.; Zhu, T.J.; Wei, H.J.; Zhang, G.Q.; Wang, H.; Gu, Q.Q. Spicochalasin A and new aspochalasins from the marine-derived fungus Spicaria elegans. Eur. J. Org. Chem. 2009, 18, 3045-3051. [CrossRef]

10. Wang, F.Z.; Wei, H.J.; Zhu, T.J.; Li, D.H.; Lin, Z.J.; Gu, Q.Q. Three new cytochalasins from the marine-derived fungus Spicaria elegans KLA03 by supplementing the cultures with $L$ - and $D$-tryptophan. Chem. Biodivers. 2011, 8, 887-894. [CrossRef]

11. Zhang, A.H.; Wang, X.Q.; Han, W.B.; Sun, Y.; Guo, Y.; Guo, Y.; Wu, Q.; Ge, H.M.; Song, Y.C.; Ng, S.W.; et al. Discovery of a new class of immunosuppressants from Trichothecium roseum co-inspired by cross-kingdom similarity in innate immunity and pharmacophore motif. Chem. Asian J. 2013, 8, 3101-3107. [CrossRef] [PubMed]

12. Wang, B.; Kang, Q.J.; Lu, Y.Z.; Bai, L.Q.; Wang, C.S. Unveiling the biosynthetic puzzle of destruxins in Metarhizium species. Proc. Natl. Acad. Sci. USA 2012, 109, 1287-1292. [CrossRef] [PubMed]

13. Liu, B.L.; Tzeng, Y.M. Development and applications of destruxins: A review. Biotechnol. Adv. 2012, 30, $1242-1254$. [CrossRef] [PubMed]

14. Yoshida, M.; Takeuchi, H.; Ishida, Y.; Yashiroda, Y.; Yoshida, M.; Takagi, M.; Shi-ya, K.; Doi, T. Synthesis, structure determination, and biological evaluation of Destruxin E. Org. Lett. 2010, 12, 3792-3795. [CrossRef] [PubMed]

15. Chen, H.C.; Chou, C.K.; Sun, C.M.; Yeh, S.F. Suppressive effects of destruxin B on hepatitis B virus surface antigen gene expression in human hepatoma cells. Antivir. Res. 1997, 34, 137-144. [CrossRef]

16. Pedras, M.S.C.; Chumala, P.B.; Wei, J.; Islam, M.S.; Hauck, D.W. The phytopathogenic fungus Alternaria brassicicola: Phytotoxin production and phytoalexin elicitation. Phyotochemistry 2009, 70, $394-402$. [CrossRef] [PubMed]

17. Zhang, M.; Zhao, J.L.; Liu, J.M.; Chen, R.D.; Xie, K.B.; Chen, D.W.; Feng, K.P.; Zhang, D.; Dai, J.G. Neural anti-inflammatory sesquiterpenoids from the endophytic fungus Trichoderma sp. Xy24. J. Asian Nat. Prod. Res. 2017, 19, 651-658. [CrossRef] [PubMed]

18. Langhanki, J.; Rudolph, K.; Erkel, G.; Opatz, T. Total synthesis and biological evaluation of the natural product (-)-cyclonerodiol, a new inhibitor of IL-4 signaling. Org. Biomol. Chem. 2014, 12, 9707-9715. [CrossRef] 
19. Wu, S.H.; Zhao, L.X.; Chen, Y.W.; Huang, R.; Miao, C.P.; Wang, J. Sesquiterpenoids from the endophytic fungus Trichoderma sp. PR-35 of Paeonia delavayi. Chem. Biodivers. 2011, 8, 1717-1723. [CrossRef]

20. Du, F.Y.; Li, X.M.; Zhang, P.; Li, C.S.; Cui, C.M.; Wang, B.G. Cyclodepsipeptides and other O-containing heterocyclic metabolites from Beauveria felina EN-135, a marine-derived entomopathogenic fungus. Mar. Drugs 2014, 12, 2816-2826. [CrossRef]

21. Du, F.Y.; Zhang, P.; Li, X.M.; Li, C.S.; Cui, C.M.; Wang, B.G. Cyclohexadepsipeptides of the isaridin class from the marine-derived fungus Beauveria felina EN-135. J. Nat. Prod. 2014, 77, 1164-1169. [CrossRef] [PubMed]

22. Du, F.Y.; Li, X.; Li, X.M.; Zhu, L.W.; Wang, B.G. Indolediketopiperazine alkaloids from Eurotium cristatum EN-220, an endophytic fungus isolated from the marine alga Sargassum thunbergii. Mar. Drugs 2017, 15, 24. [CrossRef] [PubMed]

23. Laurent, D.; Goasdoue, N.; Kohler, F.; Pellegrin, F.; Platzer, N. Characterization of cyclonerodiol isolated from corn infested by Fusarium moniliforme Sheld.: One- and two-dimensional ${ }^{1} \mathrm{H}$ and ${ }^{13} \mathrm{C}$ NMR Study. Magn. Reson. Chem. 1990, 28, 662-664. [CrossRef]

24. Liang, X.R.; Miao, F.P.; Song, Y.P.; Liu, X.H.; Ji, N.Y. Citrinovirin with a new norditerpene skeleton from the marine algicolous fungus Trichoderma citrinoviride. Bioorg. Med. Chem. Lett. 2016, 26, 5029-5031. [CrossRef] [PubMed]

25. Evans, R.; Hanson, J.R.; Nyfeler, R. The biosynthesis of the sesquiterpenoids, cyclonerodiol and cyclonerotriol. J. Chem. Soc. Chem. Commun. 1975, 20, 814-815. [CrossRef]

26. Evans, R.; Hanson, J.R.; Nyfeler, R. Studies in terpenoid biosynthesis. Part XVII. Biosynthesis of the sesquiterpenoids cyclonerodiol and cyclonerotriol. J. Chem. Soc. Perkin Trans. 1 1976, 11, 1214-1217. [CrossRef]

27. Cane, D.E.; Iyengar, R.; Shiao, M. Cyclonerodiol biosynthesis and the stereochemistry of the conversion of farnesyl to nerolidyl pyrophosphate. J. Am. Chem. Soc. 1978, 100, 7122-7125. [CrossRef]

28. Gupta, S.; Roberts, D.W.; Renwick, J.A.A. Insecticidal cyclodepsipeptides from Metarhizium anisopliae. J. Chem. Soc. Perkin Trans. 1 1989, 2347-2357. [CrossRef]

29. Tsunoo, A.; Kamijo, M.; Taketomo, N.; Sato, Y.; Ajisaka, K. Roseocardin, a novel cardiotonic cyclodepsipeptide from Trichothecium roseum TT103. J. Antibiot. 1997, 50, 1007-1013. [CrossRef]

30. Morais-Urano, R.P.; Chagas, A.C.S.; Berlinck, R.G.S. Acaricidal action of destruxins produced by a marine-derived Beauveria felina on the bovine tick Rhipicephalus (Boophilus) microplus. Exp. Parasitol. 2012, 132, 362-366. [CrossRef]

31. Xie, L.R.; Li, D.Y.; Li, Z.L.; Hua, H.M.; Wang, P.L.; Wu, X. A new cyclonerol derivative from a marine-derived fungus Ascotricha sp. ZJ-M-5. Nat. Prod. Res. 2013, 27, 847-850. [CrossRef] [PubMed]

32. Xiao, J.; Zhang, Q.; Gao, Y.Q.; Tang, J.J.; Zhang, A.L.; Gao, J.M. Secondary metabolites from the endophytic Botryosphaeria dothidea of Melia azedarach and their antifungal, antibacterial, antioxidant, and cytotoxic activities. J. Agric. Food Chem. 2014, 62, 3584-3590. [CrossRef] [PubMed]

33. Li, H.; Xiao, J.; Gao, Y.Q.; Tang, J.J.; Zhang, A.L.; Gao, J.M. Chaetoglobosins from Chaetomium globosum, an endophytic fungus in Ginkgo biloba, and their phytotoxic and cytotoxic activities. J. Agric. Food Chem. 2014, 62, 3734-3741. [CrossRef] [PubMed]

34. Ma, Y.M.; Liang, X.A.; Zhang, H.C.; Liu, R. Cytotoxic and antibiotic cyclic pentapeptide from an endophytic Aspergillus tamarii of Ficus carica. J. Agric. Food Chem. 2016, 64, 3789-3793. [CrossRef] [PubMed]

35. Dornetshuber-Fleiss, R.; Heffeter, P.; Mohr, T.; Hazemi, P.; Kryeziu, K.; Seger, C.; Berger, W.; Lemmens-Gruber, R. Destruxins: Fungal-derived cyclohexadepsipeptides with multifaceted anticancer and antiangiogenic activities. Biochem. Pharmacol. 2013, 86, 361-377. [CrossRef] [PubMed]

36. Wang, Z.Q.; Zhou, H.; Han, J.; He, Y.Q.; Lu, L.P. Evaluate insecticidal activity using Artemia salina L. Agrochemicals 2011, 50, 261-263.

37. Yao, C.C. Development and Application of Artemia nauplii Screening Method for Insecticidal Activities of Bamboo Extracts. Master's Thesis, Anhui Agricultural University, Hefei, China, June 2009.

38. Zhang, D.L.; Wang, H.Y.; Ji, X.X.; Wang, K.Y.; Wang, D.; Kang, Q. Effect of abamectin on the cereal cyst nematode (CCN, Heterodera avenae) and wheat yield. Plant Dis. 2017, 101, 973-976. [CrossRef]

39. Sheldrick, G.M. SADABS, Software for Empirical Absorption Correction; University of Göttingen: Göttingen, Germany, 1996.

40. Sheldrick, G.M. SHELXTL, Structure Determination Software Programs; Bruker Analytical X-ray System Inc.: Madison, WI, USA, 1997. 
41. Sheldrick, G.M. SHELXL-97 and SHELXS-97, Program for X-ray Crystal Structure Solution and Refinement; University of Göttingen: Göttingen, Germany, 1997.

42. Zhang, X.M.; Li, G.H.; Ma, J.; Zeng, Y.; Ma, W.G.; Zhao, P.J. Endophytic fungus Trichothecium roseum LZ93 antagonizing pathogenic fungi in vitro and its secondary metabolites. J. Microbiol. 2010, 48, 784-790. [CrossRef] 